\title{
THE ENHANCED TOLERANCE OF INVASIVE ALTERNANTHERA PHILOXEROIDES OVER NATIVE SPECIES UNDER SALT-STRESS IN CHINA
}

\author{
JAVED, Q. ${ }^{1}-$ SUN, J. ${ }^{1 *}$ - AZEEM, A. ${ }^{1}-$ UlLAH, I. ${ }^{1}-$ HUANG, P. ${ }^{1}-$ KAMA, R. ${ }^{1}-$ JABRAN, K. ${ }^{3}-$ DU, D. ${ }^{1,2^{*}}$ \\ ${ }^{1}$ School of the Environment and Safety Engineering, Jiangsu University, Zhenjiang 212013, China \\ ${ }^{2}$ Key Laboratory of Modern Agricultural Equipment and Technology, Ministry of Education, \\ Institute of Agricultural Engineering, Jiangsu University, Zhenjiang, Jiangsu, China \\ ${ }^{3}$ Department of Plant Production and Technologies, Faculty of Agricultural Sciences and \\ Technologies, Niğde Ömer Halisdemir University, Niğde, Turkey \\ *Corresponding authors \\ e-mail:ddl@ujs.edu.cn(D.L.Du),zxsjf@ujs.edu.cn(J.F.Sun); phone/fax: +86-511-8879-
} 0955

(Received $13^{\text {th }}$ Jun 2019; accepted $2^{\text {nd }}$ Sep 2019)

\begin{abstract}
Effects of environmental stress (e.g. salt stress) on the plant invasions are still relatively unknown. Therefore, we analyzed the physiological characteristics of Alternanthera philoxeroides (Mart.) Griseb. as an invasive plant and Alternanthera sessilis (L.) R.Br. ex DC. as a native plant under single and mixed planting, in green house, Jiangsu University, China. Plants were subjected to four different levels of salt stress treatments "i.e.", control, low (0.8\%), medium (1.6\%) and high $(2.4 \%)$ that were made with equal proportion of $\mathrm{NaCl}$ and $\mathrm{CaCl}_{2}$ followed by rewatering. The results showed, that different levels of salt stress affect the plant growth of both species differently. The net photosynthetic rate ( $\mathrm{Pn})$ for $A$. philoxeroides was higher from low to high stress of both single and mixed planting that of $A$. sessilis. Afterwards, during rewatering, the increments in Pn from low to high salt stress were also found higher in A. philoxeroides. In addition, the reduction in photosynthetic activity in A. sessilis under mixed planting during salt stress markedly affected the plant growth. After rewatering the comparative increments in plant growth parameter were also noted higher in A. philoxeroides than A. sessilis. Our results thus suggest that $A$. philoxeroides may possess a better adaptability to salt stress, which results in a successful competitive dominance.
\end{abstract}

Keywords: invasiveness, growth, mixed planting, physiological responses, salt tolerance

\section{Introduction}

Biological invasions are among the major global environmental challenges that can cause disturbing effects on the ecosystems (Quinet et al., 2015; Ricciardi et al., 2017; Zenni et al., 2017; Vitousek et al., 1997). Invasive plants may change the ecosystems by threatening the native biodiversity (Schweiger et al., 2010; Vilà et al., 2011). Certain non-native plant species possess some opportunistic characteristics that increase their probability to become invasive. It is related to their ability to proliferate, grow rapidly from germination to reproductive stage, and particularly, their tolerance to the environmental stresses (Van Kleunen et al., 2010). Invasive species compete with natives through a strategy known as jack-of-all-trades, which states that, the invasive species has an ability to maintain their fitness in unfavorable and stressful conditions (Richards et al., 2006), and under favorable conditions they maximize their fitness (Gioria and Osborne, 2014). It has also been well known that invasive plants have a stronger ability for adaptation than native species to heterogeneous environments (Keser 
et al., 2015; Drenovsky et al., 2012). Nonetheless, our knowledge is still limited about the survival, tolerance and competitive dominance of invasive plants over native plants regarding why and how they adapt to heterogeneous abiotic factors.

Among heterogeneous abiotic factors, salt stress is one of the major abiotic concerns, threatening crop productivity (Asrar et al., 2017). Salinity may play an imperative part in the plant invasiveness. Up to now, limited research work has been conducted in the area of the impact of salt stress on plant invasion, and some contradictory results were revealed by a few researchers. As Kolb and Alpert (2003) exhibited high salt stress significantly decreased the relative-competitive-ability of the native species. Whereas, Noe and Zedler (2001) pointed out that salt stress was affecting the invasion by invasive species. The two key principals through which high-salt-levels stressed the plants are: (i) increase in osmotic potential imposed water-stress on plants by the result of high solute concentrations in the soil, and (ii) oxidative stress caused by high-concentration of nonessential-ions is poisonous to plants (Flexas et al., 2012).

Stress causes the changes in cell-water relationships and the ability of the plant to absorb water from the root zone decreases gradually (Ashraf and Foolad, 2007). The decrease in the amount of available water affects the plant growth development (Memon et al., 2010; Habib et al., 2012). In saline-conditions, salinity disturbed the plants' morphological, physiological and biochemical processes. Particularly, its limiting the plant growth (Meloni et al., 2004; Sekmen et al., 2007; Amirjani, 2010) by damaging the net photosynthetic rate $(\mathrm{Pn})$, stomatal conductance $(\mathrm{gs})$, transpiration $(\mathrm{E})$ and leaf water potential ( $\Psi^{\mathrm{LW}}$ ) (Van Kleunen et al., 2010; Azeem et al., 2017b; Zheng et al., 2009). Each parameter which is affected, influenced by many factors up to some extent, including the stress severity and the total duration (Nawaz et al., 2010), the plants species and genotypes (Croser et al., 2001; Morais et al., 2012), the concentration of saline solution (Kosma and Jenks, 2007).

The effects of salt stress on physiological features can be alleviated and recovered through rewatering. Rewatering of saline water is a good approach for a plant to recover and sustain its growth and improve plant survival under salinity stressed environment (Javed et al., 2018). Invasive plants may become more competitive than their cooccurring native plants due to their better adaptation under increasing salt stress (Ozaslan et al., 2016) following rewatering. Therefore, we selected invasive and native species for this research to find out the physiological responses under salt stresses which are rarely tested before. Alternanthera philoxeroides (Mart.) Griseb. was taken as invasive species for this research. It mainly spreads by stem and root sprouts and causes serious environmental problems globally. A. philoxeroides is a clonal invasive weed, native to South America but growing in both riparian strip and terrestrial zones (You et al., 2018; Schooler, 2012). While, Alternanthera sessilis (L.) known as sessile joyweed, was considered as native species. It is a very common plant found in Brazil and in many tropical and subtropical areas of Africa, South Asia, Japan, New Zealand, Pacific Islands, Central America and South America. A. sessilis prefers wet surroundings but can grow under a variety of soil conditions (Gunasekera, 2008). Consequently, this study could be a little contribution to our knowledge about the invasiveness of $A$. philoxeroides in saline conditions. To justify this statement, the purpose of this research was to examine how A. philoxeroides and A. sessilis respond to salt stress followed by rewatering based on physiological properties. Meanwhile, the study also focused on the competitive growth among $A$. philoxeroides and A. sessilis under stress and rewatering during mixed planting. 


\section{Materials and methods}

\section{Species}

Alternanthera philoxeroides (Mart.) Griseb is native to the high temperate region of South America . Except from the temperature zones, it has been also found in both aquatic and as well as in dry terrestrial habitats, and it continues to expand its range around the world. A. philoxeroides is considered as an invasive species in China, has phenotypic plasticity, high growth rate and more vegetative propagation (Chen et al., 2008, 2010; Yang et al., 2019). It mainly reproduces through stem and root splitting (Dong et al., 2010).

Alternanthera sessilis (L.) is native to Brazil, broadly distributed all over the tropic and sub-tropic regions of the word. A. sessilis prefers wetland areas and grows up to 1 $\mathrm{m}$ tall with white flowers. A. sessilis is a common leafy-vegetable, and is used as a medicinal plant in South-East- Asia. While, in many places of the world like Sri Lanka, the stems and leaves of $A$. sessilis are cooked and eaten as a vegetable (Hemakanthi de Alwis et al., 2006). In Tropical-Africa, A. sessilis is used in different ways, such as sauces and soup in Benin, as soup in Nigeria, as herb in Madagascar and as vegetable in Guinea. A. sessilis is also used for simple stomach problem, diarrhea, and as a plaster for diseased or wounded skin (Gunasekera, 2008; Niraimathi et al., 2013; Sun et al., 2010).

\section{Site, culture condition and plant material}

The experiment was carried out at Jiangsu University, China $\left(32.20^{\circ} \mathrm{N}, 119.45^{\circ} \mathrm{E}\right)$ (Fig. 1) under greenhouse conditions in early September 2018. The greenhouse had natural lighting with $(25 / 18) \pm 2{ }^{\circ} \mathrm{C}$ (day/night) temperature and $70 \%$ relative humidity. A. philoxeroides and A. sessilis were chosen for this experiment, and about 360 ramets per species were collected from the same habitat at the main campus of Jiangsu University. Afterwards, the ramets of both species were grown in nutrient soil filled plastic pots. The chemical and physical characteristics of the nutrient soil were: $\mathrm{pH} 7.0$, organic matter $38 \%$, total nutrients $3.8 \%$, water content $20 \%$ and electrical conductivity of $2 \mathrm{ds} / \mathrm{m}$. while, the size of experimental pots were: outer diameter $21 \mathrm{~cm}$, inner diameter $17.7 \mathrm{~cm}$, bottom diameter $11.4 \mathrm{~cm}$ and height $12 \mathrm{~cm}$. All pots were randomly arranged and the plant of both species were planted with different densities in mono (2: 0, 0:2) and mixed planting (2: 2). Each group was irrigated with strengthen Hoagland solution as compound fertilizer to meet the basic requirements and healthy growth of seedlings for a week to keep the plants at full water level without shortage level to a total of seven weeks. After one-week plants were irrigated with fresh water every two days up to saturation levels. In the $2^{\text {nd }}$ week of September, 2019, homogenous seedlings showing a healthy growth about 240 ramets per species were selected for treatments' implementation.

\section{Treatments}

Plants were treated with different concentrations of salted water for two weeks, which were prepared by mixing equal quantities (1:1) of $\mathrm{NaCl}$ and $\mathrm{CaCl}_{2}$ in fresh water. Salt concentrations were i) control (0\%), ii) $0.8 \%$, iii) $1.6 \%$, and vi) $2.4 \%$ per liter of fresh water. The division of the treatments for A. philoxeroides and A. sessilis under single and mixed planting were; AP0: Control received $0 \%$ of $\mathrm{NaCl}$ and $\mathrm{CaCl}_{2}$; 
AP1 received $0.8 \%$ of $\mathrm{NaCl}$ and $\mathrm{CaCl}_{2} ; \mathrm{AP} 2$ received $1.6 \%$ of $\mathrm{NaCl}$ and $\mathrm{CaCl}_{2} ; \mathrm{AP} 3$ received $2.4 \%$ of $\mathrm{NaCl}$ and $\mathrm{CaCl}_{2}$; ASO: control received $0 \%$ of $\mathrm{NaCl}$ and $\mathrm{CaCl}_{2} ; \mathrm{AS} 1$ received $0.8 \%$ of $\mathrm{NaCl}$ and $\mathrm{CaCl}_{2} ; \mathrm{AS} 2$ received $1.6 \%$ of $\mathrm{NaCl}$ and $\mathrm{CaCl}_{2} ; \mathrm{AS} 3$ received $2.4 \%$ of $\mathrm{NaCl}$ and $\mathrm{CaCl}_{2}$; MAP0: control received $0 \%$ of $\mathrm{NaCl}$ and $\mathrm{CaCl}_{2}$; MAP1 received $0.8 \%$ of $\mathrm{NaCl}$ and $\mathrm{CaCl}_{2}$; MAP2 received $1.6 \%$ of $\mathrm{NaCl}$ and $\mathrm{CaCl}_{2}$; MAP3 received $2.4 \%$ of $\mathrm{NaCl}$ and $\mathrm{CaCl}_{2}$; MAS0: received $0 \%$ of $\mathrm{NaCl}$ and $\mathrm{CaCl}_{2}$; MAS1 received $0.8 \%$ of $\mathrm{NaCl}$ and $\mathrm{CaCl}_{2}$; MAS2 received $1.6 \%$ of $\mathrm{NaCl}$ and $\mathrm{CaCl}_{2}$; MAS3 received $2.4 \%$ of $\mathrm{NaCl}$ and $\mathrm{CaCl}_{2}$, respectively following rewatering. Control treatment received only the fresh water (Table 1).

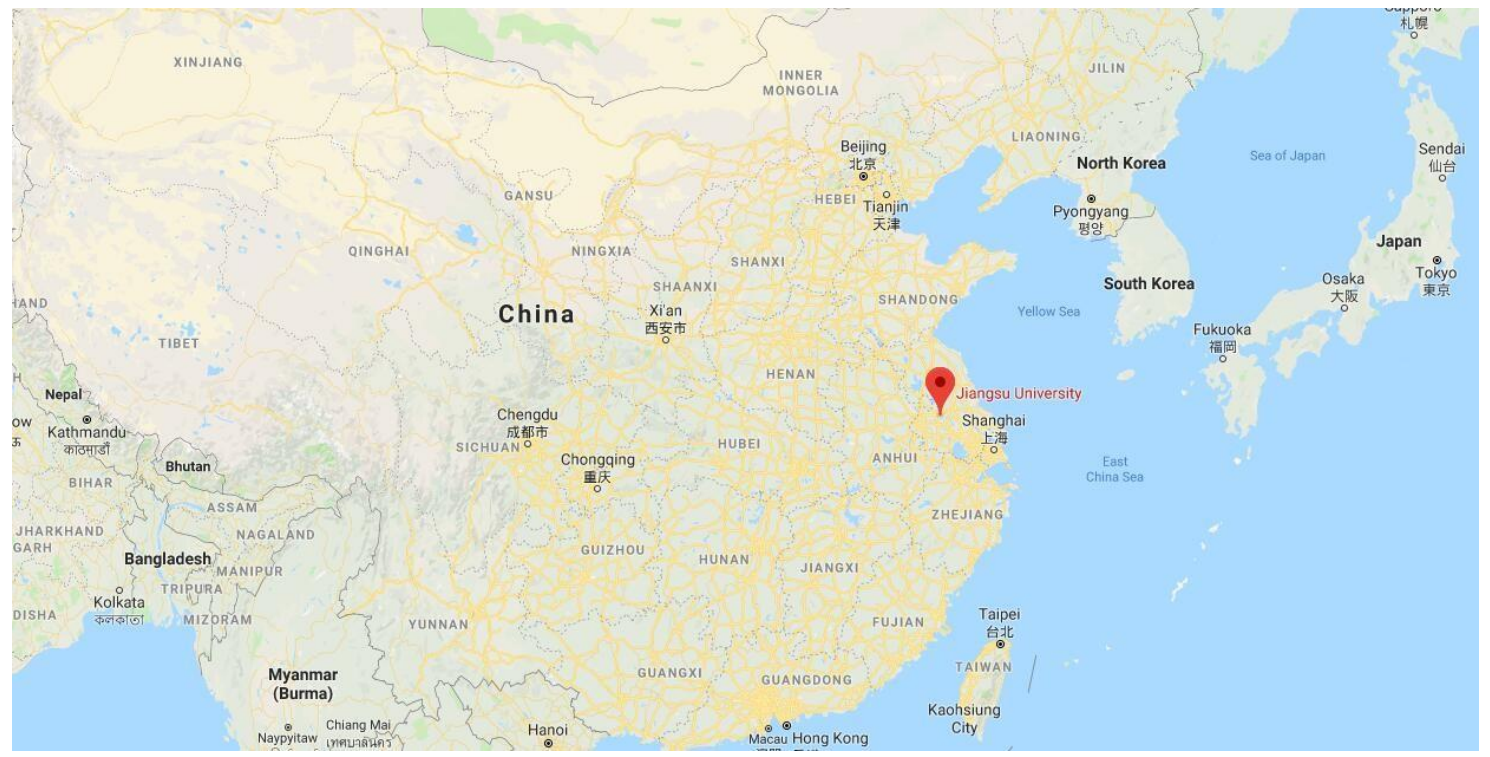

Figure 1. A map indicating the location of the sampling site

Rewatering was done on the $5^{\text {th }}$ week from the onset of salt-stress treatments. The order of rewatering is shown in Figure 2. The experiment was conducted in randomized-block-design and a total of five replicates were chosen for each physiological measurement.

\section{Photosynthetic traits and growth parameter measurements}

Net photosynthetic rate $(\mathrm{Pn})$, stomata conductance $(\mathrm{gs})$, and transpiration rate $(\mathrm{E})$ were measured by using a portable LI-6400XT photosynthesis measurement system (LICOR, Lincoln, NE, USA. We prefer the growing young leaves from the top rather than mature old leaves to check photosynthesis response and growth traits of $A$. philoxeroides and A. sessilis in salt-stress phase following rewatering. All these data were recorded during full-sunshine at 9:30-11:30 a.m. after every four days in both salt stress and rewatering phase, respectively. Five plants from each treatment group were selected for the measurement. The following settings were noted during data collection: photosynthetic active radiation (PAR) was $800 \mu \mathrm{mol} \mathrm{m}^{-2} \mathrm{~s}^{-1}$, temperature $28{ }^{\circ} \mathrm{C}$ and $\mathrm{CO}_{2}$ concentration was $500 \mu \mathrm{mol} \mathrm{mol}{ }^{-1}$.

Growth measurements were considered after salt stress and after rewatering in both cases. The measurements chosen for growth traits analysis were: plant's height $(\mathrm{PH})$; stem-diameter (SD), root-length (RL), fresh-weight of shoot $\left(\mathrm{FW}^{\mathrm{S}}\right)$, dry-weight of shoot 
$\left(\mathrm{DW}^{\mathrm{S}}\right)$, fresh-weight of root $\left(\mathrm{FW}^{\mathrm{R}}\right)$ and dry-weight of root $\left(\mathrm{DW}^{\mathrm{R}}\right)$. The $\mathrm{PH}$ was measured with a tape and SD was measured with the help of digital Vernier caliper. Afterwards, $\mathrm{FW}^{\mathrm{S}}, \mathrm{DW}^{\mathrm{S}}, \mathrm{FW}^{\mathrm{R}}$ and $\mathrm{DW}^{\mathrm{R}}$ were measured by using weighing scale.

Table 1. Concentration of saline water for different treatment levels

\begin{tabular}{|c|c|c|c|c|}
\hline Treatments & \begin{tabular}{|c|} 
Division of \\
treatments' levels
\end{tabular} & \begin{tabular}{c|} 
Treatment \\
levels
\end{tabular} & $\begin{array}{l}1 \mathrm{~L} \text { fresh water medium in } \\
\text { the quantity of } \mathrm{NaCl}\left(\mathrm{g} \mathrm{L}^{-1}\right)\end{array}$ & $\begin{array}{l}1 \mathrm{~L} \text { fresh water medium in } \\
\text { the quantity of } \mathrm{CaCl}_{2}\left(\mathrm{~g} \mathrm{~L}^{-1}\right)\end{array}$ \\
\hline $0 \%$ & Control & $\begin{array}{c}\text { AS0 } \\
\text { AP0 } \\
\text { MAS0 } \\
\text { MAP0 } \\
\end{array}$ & 0.0 & 0.0 \\
\hline $0.8 \%$ & Low & $\begin{array}{c}\text { AS1 } \\
\text { AP1 } \\
\text { MAS1 } \\
\text { MAP1 }\end{array}$ & 4.0 & 4.0 \\
\hline $1.6 \%$ & Medium & $\begin{array}{c}\text { AS2 } \\
\text { AP2 } \\
\text { MAS2 } \\
\text { MAP2 } \\
\end{array}$ & 8.0 & 8.0 \\
\hline $2.4 \%$ & High & $\begin{array}{c}\text { AS3 } \\
\text { AP3 } \\
\text { MAS3 } \\
\text { MAP3 }\end{array}$ & 12.0 & 12.0 \\
\hline
\end{tabular}

AS: A. sessilis; AP: A. philoxeroides; MAS: A. sessilis under mixed planting; MAP: A. philoxeroides under mixed planting

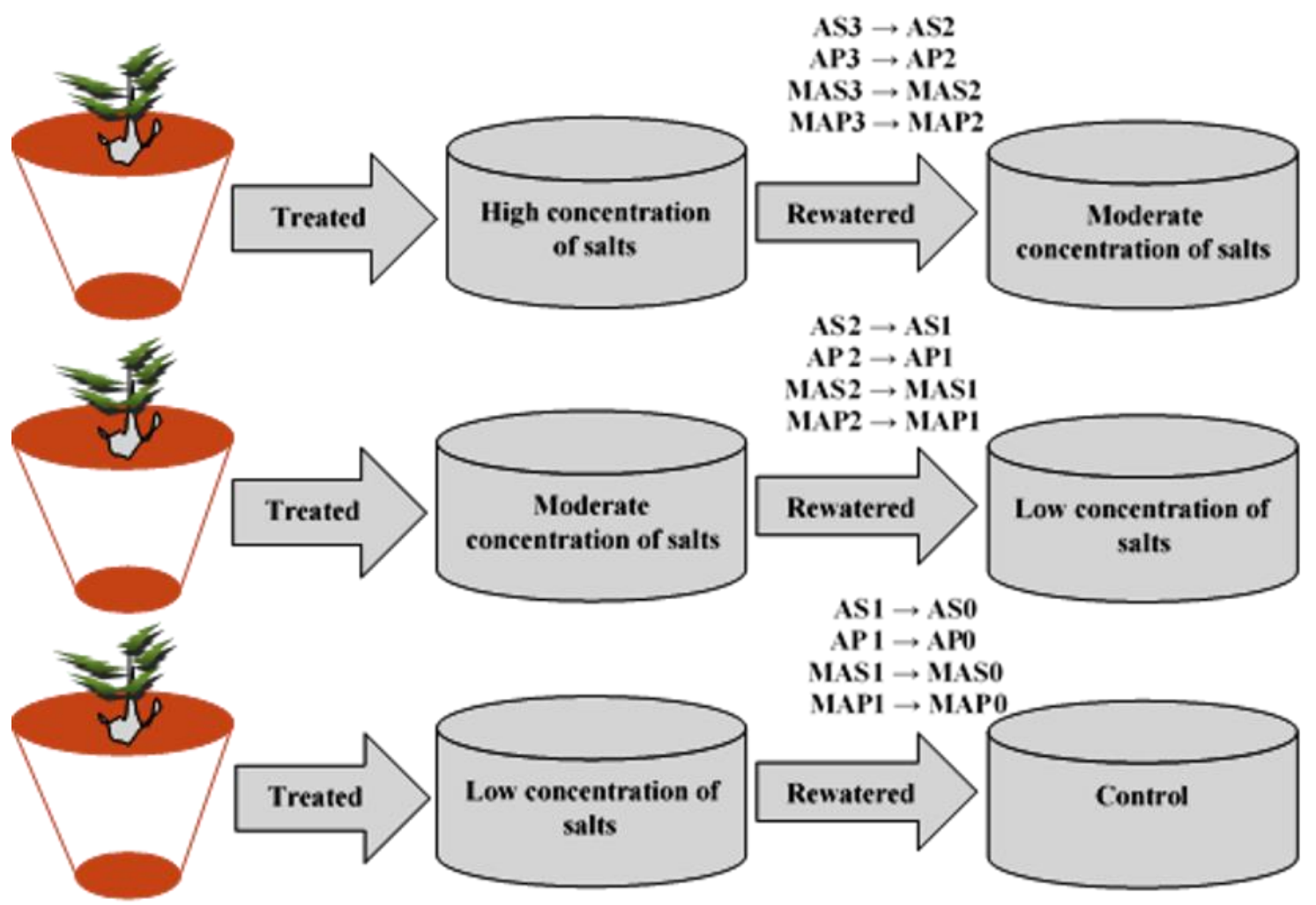

Figure 2. Rewatering order for plants treated with different concentration of salts 


\section{Leaf water potential and water use efficiency}

Leaf water potential $\left(\Psi^{\mathrm{LW}}\right)$ of $A$. philoxeroides and A. sessilis were measured by using dew point microvolt meter in a C-52-SF universal sample room (Psypro, Wescor, USA). The $\Psi^{\mathrm{LW}}$ were recorded at 9:30-11:30 a.m. in salt stress subsequently in re-watering phase, respectively. While, water use efficiency (WUE) was calculated according to Javed et al. (2018):

$$
\mathrm{WUE}=\mathrm{Pn} / \mathrm{R}_{\mathrm{T}}
$$

where $\mathrm{Pn}$ is the net photosynthetic rate and $\mathrm{R}_{\mathrm{T}}$ is the transpiration rate.

\section{Statistical analysis}

All measurements were examined statistically through SPSS 22 software (SPSS Inc., Chicago, IL, USA) and Origin Pro 9.0. Variance analysis with two crossed fixed factors was applied to discriminate the effects of species, salt stresses, rewatering and their interaction on physiological characteristics and plant growth properties under mono and mixed planting. The Tukey test was applied to determine the differences at $5 \%$ significance level $(P \leq 0.05)$ between means $(\mathrm{n}=5)$.

\section{Results}

\section{Physiological responses}

Net photosynthetic rate, stomatal conductance and transpiration

Net photosynthetic rate and stomatal conductance decreased significantly with increasing salt stress in comparison with the control. The response of the species to salt stress levels are given in Table 2. A. philoxeroides showed more tolerance from low to high concentration of salts. The values of Pn for A. philoxeroides at low concentration levels for single and mixed planting at AP1, MAP1 were 7.63 and 6.64 $\mu \mathrm{mol}\left(\mathrm{CO}_{2}\right) \mathrm{m}^{-2} \mathrm{~s}^{-1}$, higher than the values of Pn for A. sessilis, which were 6.68 and $4.90 \mu \mathrm{mol}\left(\mathrm{CO}_{2}\right) \mathrm{m}^{-2} \mathrm{~s}^{-1}$ at AS1 and MS1, respectively. It was found that, Pn was affected more under high stress at AS3, AP3, MAS3 and MAP3 in A. sessilis compared to A. philoxeroides (Fig. 3a). Upon comparing, the average Pn values of $A$. sessilis and $A$. philoxeroides, mixed planting decreased the Pn values more in $A$. sessilis respectively. Similarly, the response of the gs to salt stress levels are given in Table 2. The reduction in gs was found higher at high concentration for both $A$. philoxeroides and $A$. sessilis but comparatively less in $A$. philoxeroides. The gs values in mol $\left(\mathrm{H}_{2} \mathrm{O}\right) \mathrm{m}^{-2} \mathrm{~s}^{-1}$ for both A. philoxeroides and A. sessilis at high concentration under single and mixed planting were AS3: 0.066 AP3: 0.094 and MAS3: 0.044, MAP3: 0.086, respectively. It was showed that, during competition under mixed planting, A. sessilis exhibited maximum reduction in $N p$ and afterwards in Cs as compared to single planting (Fig. $3 b$ ).

The response of $\mathrm{Pn}$ and gs during salt stress following rewatering are also shown in (Table 2; Fig. 3a, b). It was observed that A. philoxeroides exhibited significantly better recovery from stress phase to re-watering phase. During rewatering, by comparing the means under salt stress and rewatering, the increments in Pn from low to high salt concentration $(\mathrm{AP} 1(1 \rightarrow 0)$, AP2 $(2 \rightarrow 1)$, AP3 $(3 \rightarrow 2))$ for single- $A$. 
philoxeroides were $21.50 \%, 19.95 \%$ and $13.70 \%$ but for single-A. sessilis, increments in $\mathrm{Pn}$ at $\mathrm{AS} 1(1 \rightarrow 0), \operatorname{AS} 2(2 \rightarrow 1), \operatorname{AS} 3(3 \rightarrow 2)$ were noted as $16.04 \%, 10.23 \%$ and $5.34 \%$, respectively. The Pn was not recovered well even after rewatering in case of mix-A. sessilis and showed less recovery comparatively to mix-A. philoxeroides (Fig. $3 a$ ). In rewatering phase, the increments in gs under low to high salt stress were found lower in A. sessilis plants (Fig. 3b). Consequently, high salt stresses affected gs and left adverse effect under mixed planting (Table 2; Fig. 3b).
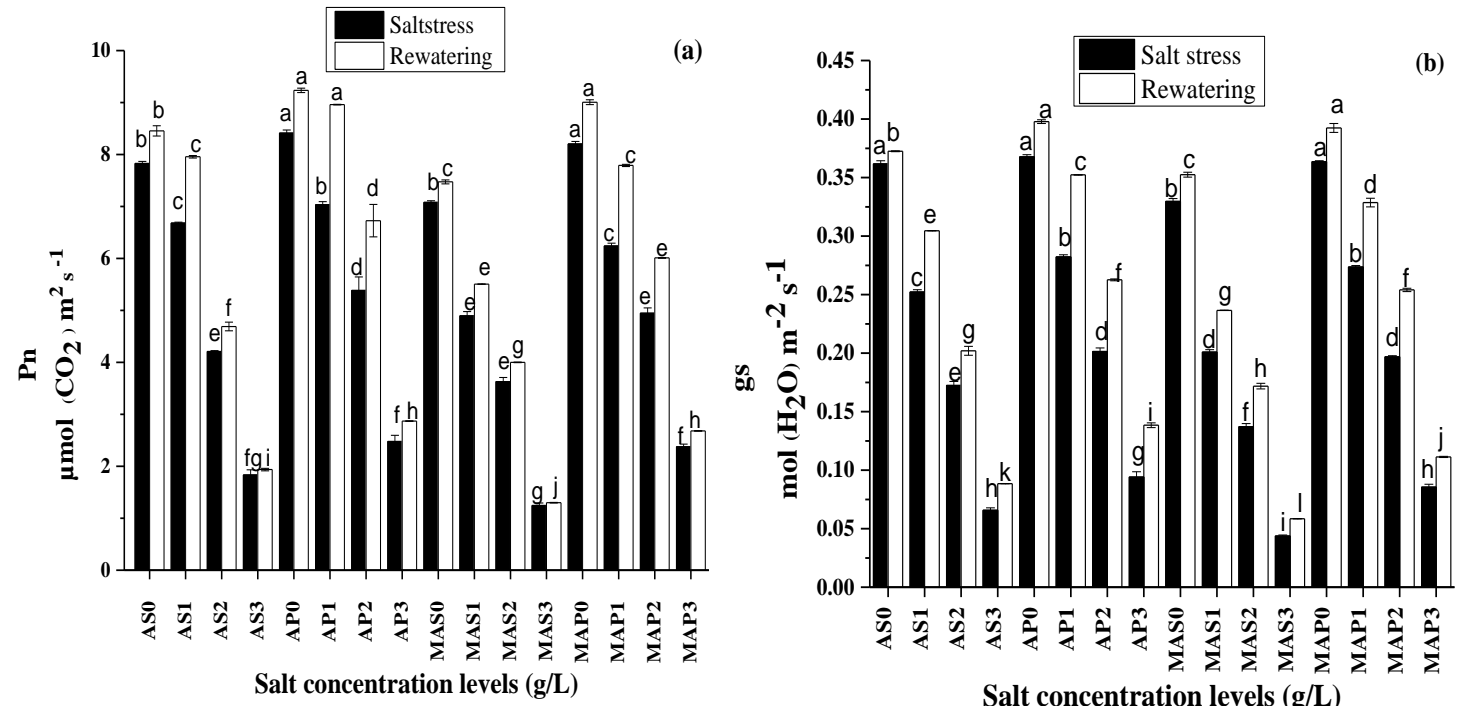

Figure 3. Subsequent impact of salt stress under rewatering on (a) net photosynthetic rate and (b) stomatal conductance of A. philoxeroides and A. sessilis under single and mixed planting. Mean values sharing different letters are significantly different at $p \leq 0.05$ under different salt treatment levels

\section{Transpiration, water use efficiency and leaf water potential}

Table 2 represented the results of E, WUE and $\Psi^{\mathrm{LW}}$. The results exhibited the significant differences among treatment species and their interactions. The values of $\mathrm{E}$ decreased during salt treatments at low to high concentration levels, as compared to control (Table 2). Transpiration of A. sessilis decreased significantly in the stress and recovered up to moderate level AS2 for single planting during re-watering phase as shown in Figure 4a. But the salt stress severely affected A. sessilis E at AS3 and it did not recover. The E declined in A. philoxeroides throughout salt treatments at low to high concentration levels, as compared to control and recovered well from low to high stress. Therefore, in the rewatering phase, A. philoxeroides is also showed better $\mathrm{E}$ under mixed planting and was found to be recovering well from low MAP1 $(1 \rightarrow 0)$ to moderate level MAP2 $(2 \rightarrow 1)$ and less recovered at high level AP3 $(3 \rightarrow 2)$ and MAP3 $(3 \rightarrow 2)$ (Fig. 4a). Recovery of E confirms that A. philoxeroides can use more water to decrease the $\mathrm{E}$ and can improve plant development after rewatering. On the other hand, rewatering did not leave the positive effect on $E$ recovery of the plant during competition with $A$. philoxeroides under mixed planting. Water potential $\left(\Psi^{\mathrm{LW}}\right)$ tends to decline as the relative water content of plant leaves decreases under stress condition. According to our results, $\Psi^{\mathrm{LW}}$ was affected with increasing salt stress compared with control (Table 2). 
Table 2. Variance analysis of photosynthetic parameters of A. philoxeroides and A. sessilis under salt stress followed by rewatering

\begin{tabular}{|c|c|c|c|c|c|c|}
\hline & \multicolumn{3}{|c|}{ Salt stress } & \multicolumn{3}{|c|}{ Rewatering } \\
\hline & DF & $\mathbf{F}$ & $\mathbf{P}$ & DF & $\mathbf{F}$ & $\mathbf{P}$ \\
\hline \multicolumn{4}{|c|}{ Photosynthesis } & \multicolumn{3}{|c|}{ Photosynthesis } \\
\hline $\mathbf{T}$ & 3 & 3568.091 & 0.001 & 3 & 3997.442 & 0.001 \\
\hline $\mathbf{S}$ & 3 & 299.171 & 0.001 & 3 & 529.100 & 0.001 \\
\hline $\mathbf{T} \times \mathbf{S}$ & 9 & 15.871 & 0.001 & 9 & 20.350 & 0.001 \\
\hline \multicolumn{4}{|c|}{ Stomatal conductance } & \multicolumn{3}{|c|}{ Stomatal conductance } \\
\hline $\mathbf{T}$ & 3 & 6852.555 & 0.001 & 3 & 1470.533 & 0.001 \\
\hline $\mathbf{S}$ & 3 & 395.100 & 0.003 & 3 & 1366.023 & 0.001 \\
\hline $\mathbf{T} \times \mathbf{S}$ & 9 & 9.920 & 0.001 & 9 & 52.723 & 0.001 \\
\hline \multicolumn{4}{|c|}{ Transpiration } & \multicolumn{3}{|c|}{ Transpiration } \\
\hline $\mathbf{T}$ & 3 & 3205.679 & 0.001 & 3 & 7551.105 & 0.001 \\
\hline $\mathbf{S}$ & 3 & 486.264 & 0.004 & 3 & 1138.365 & 0.001 \\
\hline $\mathbf{T} \times \mathbf{S}$ & 9 & 2.368 & 0.007 & 9 & 106.210 & 0.110 \\
\hline \multicolumn{4}{|c|}{ Water potential } & \multicolumn{3}{|c|}{ Water potential } \\
\hline $\mathbf{T}$ & 3 & 2160.235 & 0.001 & 3 & 2345.998 & 0.001 \\
\hline $\mathbf{S}$ & 3 & 244.805 & 0.001 & 3 & 311.879 & 0.001 \\
\hline $\mathbf{T} \times \mathbf{S}$ & 9 & 22.4554 & 0.001 & 9 & 50.907 & 0.015 \\
\hline \multicolumn{4}{|c|}{ Water use efficiency } & \multicolumn{3}{|c|}{ Water use efficiency } \\
\hline $\mathbf{T}$ & 3 & 2053.659 & 0.001 & 3 & 3601.187 & 0.001 \\
\hline $\mathbf{S}$ & 3 & 1185.221 & 0.021 & 3 & 2054.185 & 0.105 \\
\hline $\mathbf{T} \times \mathbf{S}$ & 9 & 971.110 & 0.011 & 9 & 814.514 & 0.132 \\
\hline
\end{tabular}

$\mathrm{T}=$ treatments, $\mathrm{S}_{=}$species, $\mathrm{T} \times \mathrm{S}_{=}$interaction among the treatments and species, significant at $P \leq 0.001$ and $P \leq 0.005$ according to two-way ANOVA

The WUE showed the significant increase for A. sessilis from control to low stress, and the increment after rewatering was found as $31.65 \%$ and $23.55 \%$ at AS1 and MAS1 followed by medium stress $(27.55 \%, 22.03 \%)$ at AS2 and MAS2, respectively. The maximum increments in WUE were recorded under low and medium stress for $A$. philoxeroides $(36.16 \%, 32.13 \%, 33.53 \%$ and 31.90) under AP1, AP2, MAP1 and MAP2, respectively (Fig. 4b). However, the stress-persuaded maximum reduction was noted for A. sessilis under high stress at AS3 and MAS3. While comparatively, rewatering was reducing the effect of salt stresses significantly, and exposed the significant rise in WUE for A. philoxeroides (Fig. 4b).

In case of single planting of $A$. philoxeroides and $A$. sessilis, the minimum decrease in $\Psi^{\mathrm{LW}}$ was noted as $-1.18 \mathrm{MPa}$ and $-2.00 \mathrm{MPa}$ under low concentration levels at AP1 and AS1, respectively for both species as compared to moderate and high stress levels. But, the maximum decrease in $\Psi^{\mathrm{LW}}$ was noted as $-2.82 \mathrm{MPa}$ and $-3.10 \mathrm{MPa}$ at AP3 and AS3, respectively. While under mixed planting, A. sessilis is becoming more sensitive to salt stress and $\Psi^{\mathrm{LW}}$ was affected seriously from moderate to high concentrations (Fig. 5). However, in the competition, $\Psi^{\mathrm{LW}}$ was severely decreased in A. sessilis as compared to A. philoxeroides, respectively. As a comparison between single and mixed plantation, salts badly affected the $\Psi^{\mathrm{LW}}$ in $A$. sessilis than $A$. philoxeroides (Fig. 5). 


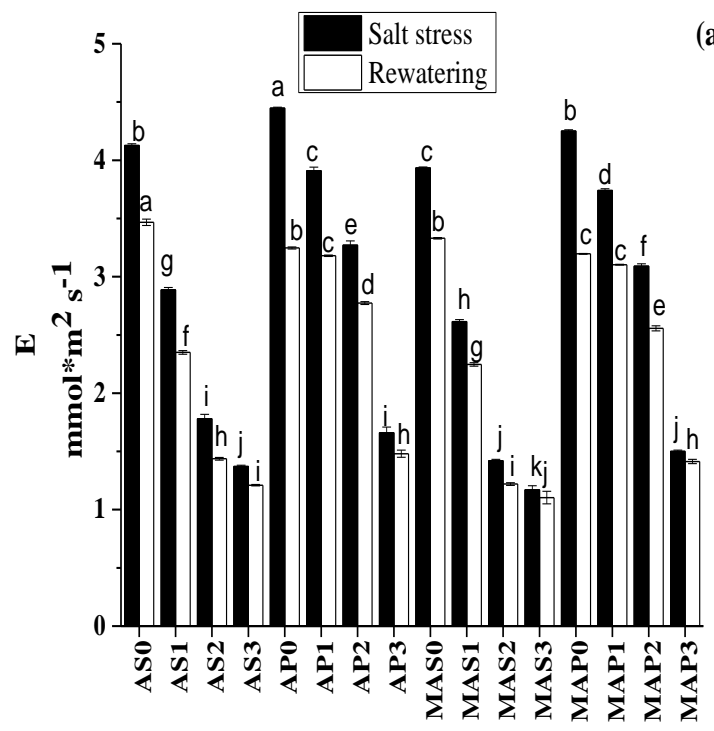

Salt concentration levels $(\mathrm{g} / \mathrm{L})$ (a)

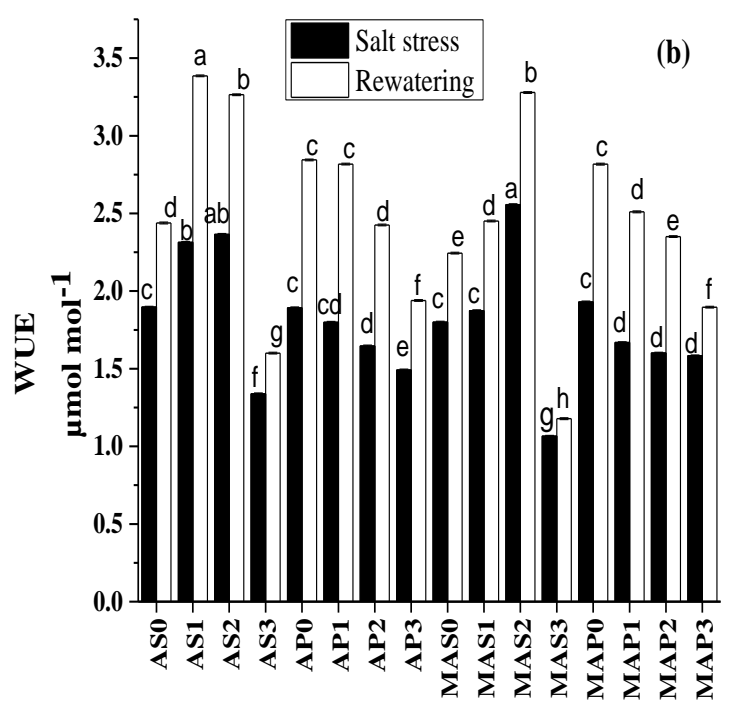

Salt concentration levels $(\mathrm{g} / \mathrm{L})$

Figure 4. Subsequent impact of salt stress under rewatering on (a) transpiration rate and (b) water use efficiency of A. philoxeroides and A. sessilis single and mixed planting. Mean values sharing different letters are significantly different at $p \leq 0.05$ under different salts treatment levels

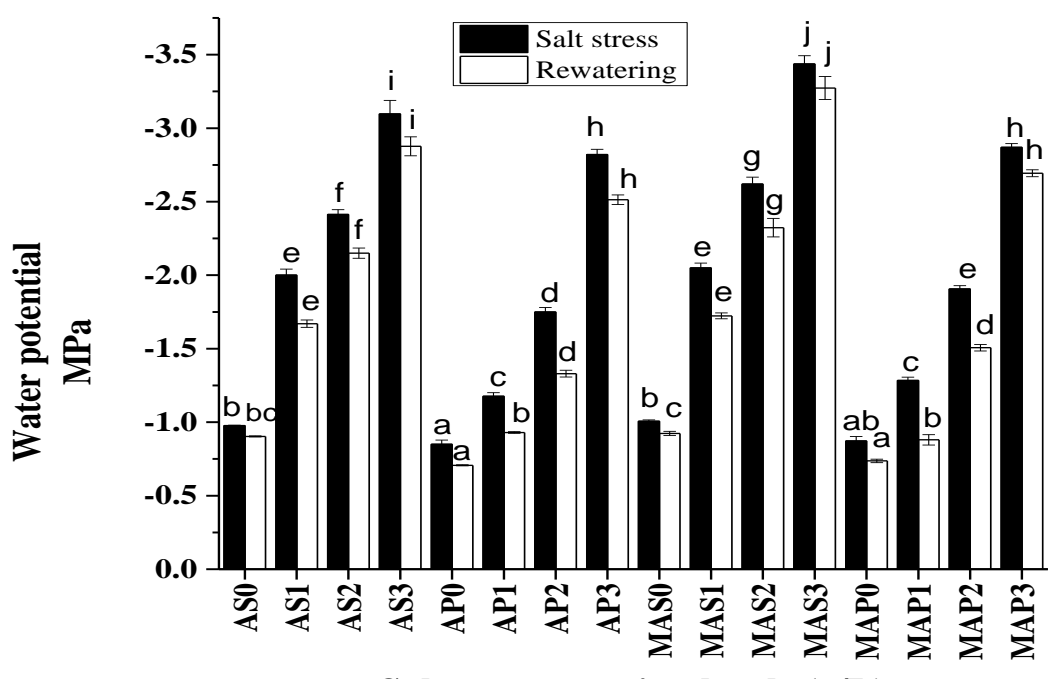

Salt concentration levels $(\mathrm{g} / \mathrm{L})$

Figure 5. Subsequent impact of salt stress under rewatering in leaf water potential of A. philoxeroides and A. sessilis under single and mixed planting. Mean values sharing different letters are significantly different at $p \leq 0.05$ under different salts treatment levels

Table 2 also presents the values of $\Psi^{\mathrm{LW}}$ in salt stress following rewatering. The recovery in $\Psi^{\mathrm{LW}}$ was found less in single-A. sessilis from low to high stress (Fig. 5). Water potential was not recovered at high concentration levels for single-A. sessilis plants. However, the degree of salts was still showed its adverse effect on A. sessilis in the increment of $\Psi^{\mathrm{LW}}$ from moderate to high stress even during re-watering under mixed planting (Fig. 5). 


\section{Plant growth responses}

\section{Plant height and stem diameter}

Stresses significantly affected the growth of A. sessilis and A. philoxeroides through reduction in plant height and stem diameter. The results showed significant differences among treatments, species and their interactions of growth parameters (Table 3). Plants growth of $A$. sessilis is more affected in competition under mixed planting as compared to A. philoxeroides (Fig. 6a, b). A. philoxeroides showed more tolerance from low to high stress in single as well as in mixed planting. Plant height and stem diameter were significant as compared to control. Upon comparing A. philoxeroides with A. sessilis under single and mixed planting, the PH $(\mathrm{cm})$ are AP1: 42.30, AS1: 36.80, AP2: 37.30, AS2: 31.80, AP3: 32.40, AS3: 28, MAP1:40.30, MAS1: 33.80, MAP2: 35.30, MAS2: 28.80, MAP3: 30.60, MAS3: 25.50 (Fig. 6a); following SD (mm) which are AP1: 3.71, AS1: 2.98, AP2: 3.42, AS2: 2.39, AP3: 2.97, AS3: 2.23, MAP1: 3.34, MAS1: 2.49, MAP2: 3.16, MAS2: 2.28, MAP3: 2.77, MAS3: 2.00 (Fig. 6b). So, the A. sessilis exposed its sensitivity during competition under mixed planting, more reduction was found in plant height and stem diameter (Fig. 6a, b).

The subsequent $\mathrm{PH}$ and SD under salt stress under rewatering are also explained in Table 3. It was observed that $A$. philoxeroides exhibited significantly better recovery from stress phase to re-watering phase. While in re-watering phase, by comparing the means, the increments in PH and SD under moderate to high salt stress was found to lower in $A$. sessilis. By comparing, relatively, more increments in $\mathrm{PH}$ and $\mathrm{SD}$ were found in $A$. philoxeroides (Fig. 6a, b). The increments in PH after rewatering are AP1: 24.60\%, AS1: 13.62\%, AP2: 17.29\%, AS2: 12.15\%, AP3: 7.95\%, AS3: 5.72\%, MAP1: 21.44\%, MAS1: 12.89\%, MAP2: 22.08\%, MAS2: 7.99\%, MAP3: 6.13\%, MAS3: 1.16\% (Fig. 6a); following by SD as AP1: $19.00 \%$, AS1: $18.36 \%$, AP2: $16.79 \%$, AS2: $13.41 \%$, AP3: 5.41\%, AS3: 2.62\%, MAP1: 21.60\%, MAS1: 17.00\%, MAP2: 15.28\%, MAS2: $9.52 \%$, MAP3: $4.48 \%$, MAS3: $1.48 \%$, respectively. Rewatering alleviate the effect of salt stress more effectively in A. philoxeroides and left positive impact on plant growth.

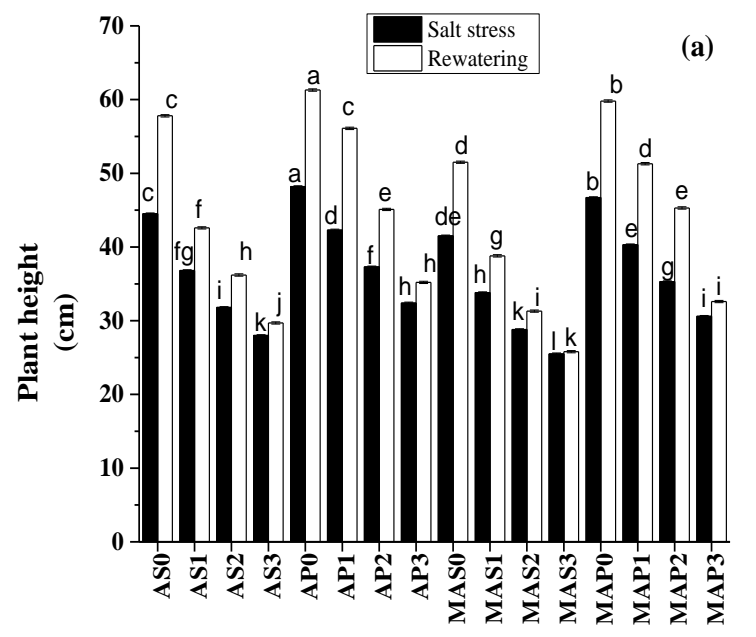

Salt concentration levels $(\mathrm{g} / \mathrm{L})$

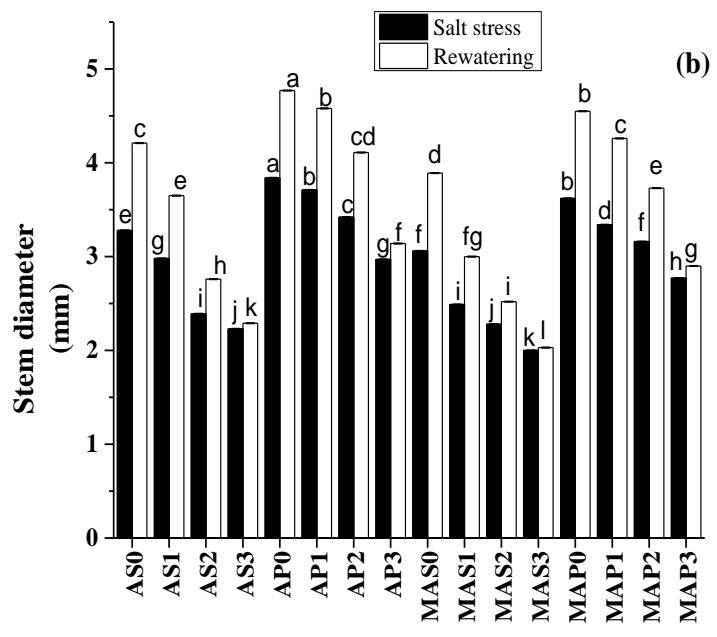

Salt concentration levels $(\mathrm{g} / \mathrm{L})$

Figure 6. Subsequent impact of salt stress under rewatering on (a) plant height and (b) stem diameter of A. philoxeroides and A. sessilis under single and mixed planting. Mean values sharing different letters are significantly different at $p \leq 0.05$ under different salts treatment levels 


\section{Fresh and dry weight of shoot}

Fresh and dry weight of shoot of both species for each treatment was presented in Table 3. As expected, mean of Fresh and dry weight decreased depending on salt concentration (Table 3; Fig. 7a, b). The variations in the results of shoot fresh and dry weight are different in both species. $\mathrm{FW}^{\mathrm{S}}$ in single-A. sessilis is relatively more affected than mono-A. philoxeroides under high salt stress as AS3: $5.60 \mathrm{~g}$, and AP3: $8.93 \mathrm{~g}$ following $\mathrm{DW}^{\mathrm{S}}$ as AS3: $0.20 \mathrm{~g}$, and AP3: $0.28 \mathrm{~g}$, respectively. While, in competition under mixed planting $\mathrm{FW}^{\mathrm{S}}$ and $\mathrm{DW}^{\mathrm{S}}$ of $A$. sessilis declined more comparatively with mixed-A. philoxeroides (Table 3; Fig. 7a). The $\mathrm{FW}^{\mathrm{S}}$ under mixed planting are MAS1: $10.30 \mathrm{~g}$, MAP1: $21.27 \mathrm{~g}$, MAS2: $5.20 \mathrm{~g}, \mathrm{MAP} 2: 12.43 \mathrm{~g}, \mathrm{MAS} 3:$ $2.57 \mathrm{~g}$, MAP3: $7.97 \mathrm{~g}$ (Fig. 3c), following DW ${ }^{\mathrm{S}}$ as MAS1: $0.37 \mathrm{~g}$, MAP1: $3.03 \mathrm{~g}$, MAS2: 0.18 g, MAP2: 0.60 g, MAS3: 0.11 g, MAP3: 0.24 g, respectively (Fig. $7 b)$. Though, A. philoxeroides showed more tolerance from low to high stress in both single and mixed planting.

Table 3. Variance analysis of plant growth parameters of A. philoxeroides and A. sessilis under salt stress followed by rewatering

\begin{tabular}{|c|c|c|c|c|c|c|}
\hline & \multicolumn{3}{|c|}{ Salt stress } & \multicolumn{3}{|c|}{ Rewatering } \\
\hline & DF & $\mathbf{F}$ & $\mathbf{P}$ & DF & $\mathbf{F}$ & $\mathbf{P}$ \\
\hline \multicolumn{4}{|c|}{ Plant height } & \multicolumn{3}{|c|}{ Plant height } \\
\hline $\mathbf{T}$ & 3 & 5598.254 & 0.001 & 3 & 19956.761 & 0.001 \\
\hline $\mathbf{S}$ & 3 & 1355.258 & 0.001 & 3 & 6534.237 & 0.001 \\
\hline $\mathbf{T} \times \mathbf{S}$ & 9 & 43.666 & 0.003 & 9 & 504.682 & 0.001 \\
\hline \multicolumn{4}{|c|}{ Stem diameter } & \multicolumn{3}{|c|}{ Stem diameter } \\
\hline $\mathbf{T}$ & 3 & 2352.250 & 0.001 & 3 & 70354.187 & 0.001 \\
\hline $\mathbf{S}$ & 3 & 2165.251 & 0.001 & 3 & 5985.843 & 0.001 \\
\hline $\mathbf{T} \times \mathbf{S}$ & 9 & 71.146 & 0.005 & 9 & 1110.258 & 0.070 \\
\hline \multicolumn{4}{|c|}{ Fresh weight of shoot } & \multicolumn{3}{|c|}{ Fresh weight of shoot } \\
\hline $\mathbf{T}$ & 3 & 3865.307 & 0.001 & 3 & 3813.078 & 0.001 \\
\hline $\mathbf{S}$ & 3 & 887.035 & 0.001 & 3 & 916.774 & 0.001 \\
\hline $\mathbf{T} \times \mathbf{S}$ & 9 & 11.948 & 0.171 & 9 & 10.115 & 0.015 \\
\hline \multicolumn{4}{|c|}{ Dry weight of shoot } & \multicolumn{3}{|c|}{ Dry weight of shoot } \\
\hline $\mathbf{T}$ & 3 & 2044.585 & 0.001 & 3 & 1669.187 & 0.001 \\
\hline $\mathbf{S}$ & 3 & 407.221 & 0.005 & 3 & 284.552 & 0.005 \\
\hline $\mathbf{T} \times \mathbf{S}$ & 9 & 6.107 & 0.071 & 9 & 29.741 & 0.011 \\
\hline \multicolumn{4}{|c|}{ Fresh weight of root } & \multicolumn{3}{|c|}{ Fresh weight of root } \\
\hline $\mathbf{T}$ & 3 & 1515.276 & 0.001 & 3 & 726.2045 & 0.001 \\
\hline $\mathbf{S}$ & 3 & 371.399 & 0.001 & 3 & 209.3972 & 0.001 \\
\hline $\mathbf{T} \times \mathbf{S}$ & 9 & 2.711 & 0.018 & 9 & 2.857 & 0.008 \\
\hline \multicolumn{4}{|c|}{ Dry weight of root } & \multicolumn{3}{|c|}{ Dry weight of root } \\
\hline $\mathbf{T}$ & 3 & 1519.2898 & 0.001 & 3 & 618.984 & 0.001 \\
\hline $\mathbf{S}$ & 3 & 182.1445 & 0.001 & 3 & 160.779 & 0.001 \\
\hline $\mathbf{T} \times \mathbf{S}$ & 9 & 26.1700 & 0.001 & 9 & 24.602 & 0.001 \\
\hline
\end{tabular}

$\mathrm{T}_{=}$treatments, $\mathrm{S}_{=}$species, $\mathrm{T} \times \mathrm{S}_{=}$interaction among the treatments and species, significant at $P \leq 0.001$ and $P \leq 0.005$ according to two-way ANOVA 

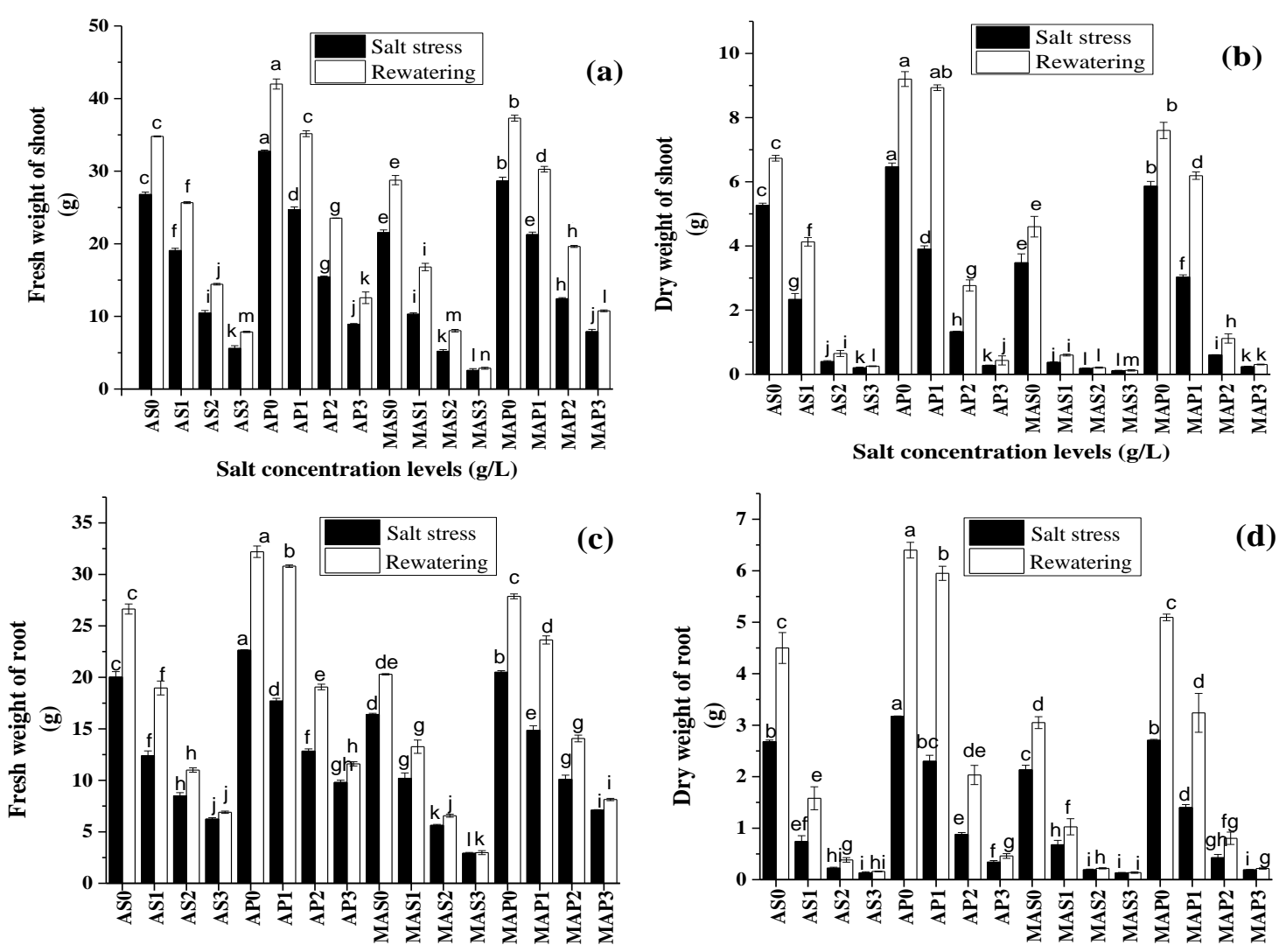

Salt concentration levels $(\mathrm{g} / \mathrm{L})$

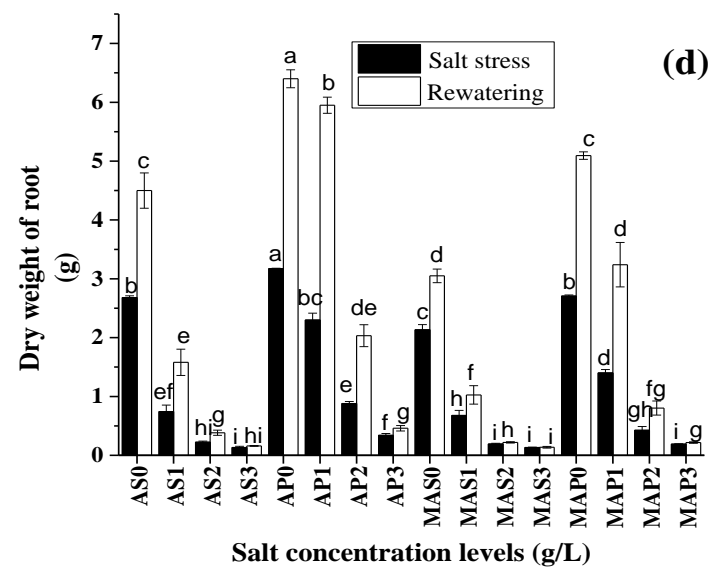

Figure 7. Subsequent impact of salt stress under rewatering on (a) fresh weight of shoot, (b) dry weight of shoot, (c) fresh weight of root, and (d) dry weight of root of A. philoxeroides and A. sessilis under single and mixed planting. Mean values sharing different letters are significantly different at $p \leq 0.05$ under different salts treatment levels

Subsequent salt stress under re-watering, is shown in Table 3 for $\mathrm{FW}^{\mathrm{S}}$ and $\mathrm{DW}^{\mathrm{S}}$. The plants showed recovery significantly from stress phase to re-watering phase (Fig. 7a, b). During re-watering phase, the increments in $\mathrm{FW}^{\mathrm{S}}$ followed by $\mathrm{DW}^{\mathrm{S}}$ under moderate to high salt stress were found to lower in A. sessilis that are AS2: 33.06\%, AP2: 67.47\% and AS3: 18.89, < AP3: 30.28\%; AS2:38.97\%, AP2: 56.27\% and AS3:19.74\%, AP3: $36.14 \%$, respectively (Fig. $7 a, b$ ). Relatively, the maximum increment in $\mathrm{FW}^{\mathrm{S}}$ and $\mathrm{DW}^{\mathrm{S}}$ was observed for single and mixed-A. philoxeroides as $87.22 \%, 71.94 \%, 56.27 \%, 51.00 \%$ while for mono and mixed $A$. sessilis, it was calculated as $66.67 \%, 60.28 \%, 43.52 \%$, $24.42 \%$ at AP1, MAP1, AS1, and MAS1, respectively (Fig. 7a, b). Comparing with other stress levels after re-watering, relatively, more decrements in $\mathrm{FW}^{\mathrm{S}}$ and $\mathrm{DW}^{\mathrm{S}}$ were found in $A$. sessilis under mixed planting and minimum recovery found after rewatering.

\section{Fresh and dry weight of root}

Fresh and dry weight of root of both species for each treatment was presented in Table 3. $\mathrm{FW}^{\mathrm{R}}$ and $\mathrm{DW}^{\mathrm{R}}$ decrease by increasing salt concentration relatively affected more in A. sessilis than A. philoxeroides under high salt stress (Table 3; Fig. 7c, d). The $\mathrm{FW}^{\mathrm{R}}$ under single planting of $A$. sessilis at high concentration was observed as AS3: $6.23 \mathrm{~g}$, and as AP3: $9.80 \mathrm{~g}($ Fig. $7 c)$ following DW ${ }^{\mathrm{R}}$ as AS3: $0.13 \mathrm{~g}$, and as AP3: $0.34 \mathrm{~g}$, 
respectively (Fig. $7 d$ ). Comparatively, the $\mathrm{FW}^{\mathrm{R}}$ of $A$. sessilis under mixed planting was affected more following the same trend by $\mathrm{DW}^{\mathrm{R}}$, respectively. Though, A. philoxeroides showed more tolerance from low to high stress in both single and mixed planting.

The $\mathrm{FW}^{\mathrm{R}}$ and $\mathrm{DW}^{\mathrm{R}}$ under salt stress following rewatering for both A. philoxeroides and A. sessilis is shown in Table 3. Recovery in $\mathrm{FW}^{\mathrm{R}}$ and $\mathrm{DW}^{\mathrm{R}}$ is initiated during rewatering phase $\left(\right.$ Fig. $7 c, d$ ). The minimum increments were noted in $\mathrm{FW}^{\mathrm{R}}$ under moderate to high salt stress for $A$. sessilis which were AS2: $22.73 \%$, AP2: $32.69 \%$ and

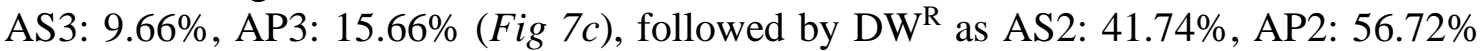
and AS3: $16.69 \%$, AP3: $26.09 \%$, respectively. The maximum increment in $\mathrm{FW}^{\mathrm{R}}$ and $\mathrm{DW}^{\mathrm{R}}$ were recorded for single and mixed-A. philoxeroides as $42.53 \%, 37.09 \%, 61.34 \%$, $56.79 \%$ and $34.62 \%, 23.12 \%, 52.96 \%, 34.09 \%$ were found for single and mixed- $A$. sessilis at AP1, MAP1, AS1, and MAS1, respectively. By comparing with other stress levels after re-watering, relatively, more decrements in $\mathrm{FW}^{\mathrm{R}}$ and $\mathrm{DW}^{\mathrm{R}}$ were found in $A$. sessilis under mixed planting even after rewatering (Fig. $7 c, d)$.

\section{Combined effect of salt stress and invasive plant on native plant}

Using the linear regression equation to develop relationship between A. philoxeroides and $A$. sessilis under salt stress levels is shown in Equation 2, as given below:

$$
\operatorname{MAS}(F W S)=0.149 \text { LsS }+1.040 \text { MAP(FWS })
$$

where $\operatorname{MAS}(F W S)$ is shoot fresh weight of A. sessilis under mixed planting; MAP(FWS) is shoot fresh weight of A. philoxeroides under mixed planting; Lss is salt stress levels.

It is well noted that the relationship between fresh weight of A. philoxeroides (MAP) under mixed planting, salt stress levels (Lss) and fresh weight of A. sessilis (MAS) under mixed planting can well characterize the combined effect of an invasive plant as A. philoxeroides and salt stress on its competitor native plant A. sessilis. The determination coefficient $\left(\mathrm{R}^{2}=0.9310\right)$, showed the best relationship between shoot fresh weight, salt stress and species and it is fitted better with the linear regression equation as compared with the other growth parameters.

\section{Discussion}

Salinity is a toxic environmental stress and severely influences several growth traits (Ashraf et al., 2012), particularly the photosynthetic rate. Salt stress initially damages the plant roots, disturbs the soil water potential and slows the growth rate of plants (Abbas et al., 2014). In our studies, the interaction between the species and salt stress has shown the significant differences (Tables 2 and 3). The salt stress limited the Pn as a result of stomata closure in both $A$. sessilis and A. philoxeroides. The Pn of A. philoxeroides and A. sessilis responded in a different way to different salt stresses (Fig. 3a). During the whole period of salt stresses, comparatively, plants kept a lower gs in single and mixed- $A$. sessilis at high salt concentrations (AS3 and MAS3) (Fig. 3b) and directly influenced the Pn. Low Pn had an adverse effect on PH and SD in A. sessilis (Fig. 6a, b), that was the cause of reduction in $\mathrm{FW}^{\mathrm{S}}, \mathrm{DW}^{\mathrm{S}}, \mathrm{FW}^{\mathrm{R}}$, and $\mathrm{DW}^{\mathrm{R}}$ (Fig. $7 a, b, c, d$ ). It may be because of the disturbed leaf-water-status caused by distribution and accumulation of salts within the plant body that in turn has a marked impact on the plant water and nutrients uptake, resulting in toxicity and low $\Psi^{\mathrm{LW}}$ (Ashraf and Foolad, 2007; Zaki, 2016). The variations 
in $\Psi^{\mathrm{LW}}$ within tissues (Fig. 4) from low (AS1, AP1, MAS1, MAP1), medium (AS2, AP2, MAS2, MAP2) and high stress (AS3, AP3, MAS3, MAP3) in both species under single and mixed planting affected the opening and closing of stomata in A. sessilis under mixed planting (Fig. 3b). It caused an imbalance in gaseous exchange, and decreased the E (Fig. $4 a$ ). Under these circumstances, plants have to utilize extra energy to make biochemical adjustments through osmolytes' accumulation for extracting water from the soil. This additional energy is diverted from the processes involved in plant growth, and results in marked reduction in yield and plant growth development (Munns and Tester, 2008; Ashraf et al., 2018), as noted in A. sessilis under single and mixed planting at AS3 and MAS3, respectively to A. philoxeroides (Figs. 6 and 7).

During competition under mixed planting, A. sessilis might be suppressed by two factors; one is competition with A. philoxeroides and other is its sensitivity to high salt stress. The combined effect of A. philoxeroides and salt stress on growth of A. sessilis is explained through linear regression ( $E q$. 2). In their meta-analysis, Van Kleunen et al. (2010), demonstrated that invasive species had higher values for numerous beneficial parameters of plant physiology, such as Pn and WUE than native species. Accordingly, $A$. philoxeroides showed photosynthetic tolerance from low stress levels (AP1 and MAP1) to high stress levels (AP3 and MAP3) under both single and mixed planting. Thus, this condition confirmed the best-threshold adaptability of photosynthetic traits and tolerance of A. philoxeroides under saline environment. Quinet et al. (2015) have also reported that Impatiens parviflora DC. is a better competitor in stress environments characterized by low water availability and shade. Impatiens parviflora copes well with shady conditions, it is tolerant to water-stress and maintains the photosynthetic activity under water-stress conditions. Ozaslan et al. (2016) did experiment on two invasive Physalis species and found that both species have a potential to withstand against water limited supply and high salinity environment. Although, WUE increased strongly in response to water stress (Fig. 4b), and plants adjusted their water potential (Fig. 4a) to maintain their water regulation for the fitness and continuation of growth. A. philoxeroides also grew well with high $\mathrm{FW}^{\mathrm{S}}, \mathrm{DW}^{\mathrm{S}}, \mathrm{FW}^{\mathrm{R}}$ and $\mathrm{DW}^{\mathrm{R}}$ and tolerate salt stresses from low to high concentration of salts at AP1, AP2, AP3 and more effectively and strongly under mixed planting at MAP1, MAP2, and MAP3 relative to its competitor A. sessilis (Fig. 7a, b, c, d). Liu et al., 2018 examined the response of three invasive and one native species under low, moderate and high water with low or high nitrogen availability. The growth, biomass and development of invasive species were higher relative to the native plant. Besides, higher salt accumulation in leaves of $A$. sessilis lowered the soil-water potential and in high stress at MAS3 prevented water uptake from soil to plant, causing dehydration of plants, with high reduction in PH, SD, (Fig. 6a, b). According to Qian and Ricklefs (2006) and Weed and Schwarzländer (2014), invasive plants have competitive advantages over neighboring native species. But these characteristics are varying from species to species and according to the kind of environmental stress (Lorenzo et al., 2010).

Rewatering relieved the stress and left better result on plant growth and development (Javed et al., 2018). But under stress, the variation in plant growth (Figs. 6a, b, 7a, b, c, d) did not associate with Pn recovery (Fig. 3a) when plant suffered under high stress conditions in A. sessilis. The production part of photosynthesis might have been used for the regeneration of ribulose-1,5-disphosphate. Therefore, at that point, an increment in Pn values for A. sessilis' plants under mixed planting noted as MAS1: 11.08\%, MAS2: 9.25\%, MAS3: 4.10\%, which was not helpful in recovery of A. sessilis' plants (Fig. 3a). However, A. philoxeroides recovered and maintained its growth and photosynthetic traits 
effectively under single planting (at AP1, AP2, and AP3) subsequent under mixed planting (at MAP1, MAP2, and MAP3) as compared to control levels. Our results supported by findings of Yousfi et al. (2016) for all species of Medicago laciniata (L.) and Xing et al. (2018) for Orychophragmus violaceus, are proposed that reduction in gs after severe drought-stress, resulted in declined Pn with slow plant growth, as found in $A$. sessilis. Thus, unhealthy growth of $A$. sessilis was observed due to inadequate wateruptake that abruptly decreased the E (Fig. 4a). Water regulation through stomata under high stress could not maintain to stable water content and is becoming the reason of reduction in leaf-water-potential. Accordingly, it was hard for A. sessilis to improve its growth after rewatering due to the excessive salts-stresses under AS3, MAS2 and MAS3, respectively.

Salt stress following rewatering is found as an important index which specifies the better growth of plant after re-watering and a good method to utilize saline water after dilution in order to safe fresh water resources (Javed et al., 2017a, b; Xing et al., 2018). Because addition in water content after re-watering was directed to the Pn increment comparatively in leaves of $A$. philoxeroides with high growth rate and biomass as $\mathrm{PH}, \mathrm{SD}$, $\mathrm{FW}^{\mathrm{S}}, \mathrm{DW}^{\mathrm{S}}, \mathrm{FW}^{\mathrm{R}}$ and $\mathrm{DW}^{\mathrm{R}}$ under both single and mixed planting conditions. The massive reduction of water potential by decreasing E under high stress exposed the wilting point, and high demand of water for plants (Azeem et al., 2017a). For that reason, it is also needed for plants to be rewatered before wilting-stage. The relative effect of salts after rewatering, under mono planting of A. philoxeroides at AP1 $(1 \rightarrow 0)$, AP2 $(2 \rightarrow 1)$, AP3 $(3 \rightarrow 2)$ was almost the same with mixed planting under MAP1 $(1 \rightarrow 0)$, MAP $(2 \rightarrow 1)$ and MAP $(3 \rightarrow 2)$, respectively. It is concluded that salts were more toxic to plant growth of $A$. sessilis under single-AP3 and all levels of mixed planting, because of its sensitive nature suppressed through competition with A. philoxeroides as an invasive plant. It is also demonstrated that $A$. philoxeroides has a good competition ability with its competitive native plant $A$. sessilis and has a stress bearing adaptability to stressful environmental conditions.

\section{Conclusions}

In this article, we identified physiological and growth traits linked to salts-stresses tolerance in A. philoxeroides and A. sessilis. The physiological and growth response confer the competitive capability to both species under stressful environment. Under salt stress followed by rewatering, A. philoxeroides had higher values of $\mathrm{Pn}, \mathrm{gs}, \Psi^{\mathrm{LW}}$, $\mathrm{PH}$ and $\mathrm{SD}$ with high biomass $\left(\mathrm{FW}^{\mathrm{S}}, \mathrm{DW}^{\mathrm{S}}, \mathrm{FW}^{\mathrm{R}}\right.$, and $\left.\mathrm{DW}^{\mathrm{R}}\right)$ than A. sessilis in both single and mixed planting. Nevertheless, the competitive ability of the invasive plant $A$. philoxeroides was higher than that of the native species $A$. sessilis under mixed planting. Comparatively, A. philoxeroides showed better effect of rewatering with good improvement in plant growth. It can be concluded that, under single and mixed planting, tolerance of $A$. philoxeroides to salt stresses and its restoration after rewatering may aid its invasion success over $A$. sessilis species. Thus this study will be an initial prediction about future distribution of $A$. philoxeroides in the saline environment. In addition for future perspective, the further study could be done by considering different environmental factors based on their biological characteristics. Therefore, investigating the relationship between plant growth and environmental factors is helpful for predicting the invasive potential of non-native plant species. 
Acknowledgements. This work was supported by State Key Research Development Program of China (2017YFC1200100), the National Natural Science Foundation of China (31971427, 31570414, and 31770446), the Priority Academic Program Development of Jiangsu Higher Education Institutions (PAPD), and Jiangsu Collaborative Innovation Center of Technology and Material of Water Treatment.

\section{REFERENCES}

[1] Abbas, T., Pervez, M., Ayyub, C., Shaheen, M., Tahseen, S., Shahid, M., Bilal, R., Manan, A. (2014): Evaluation of different Okra genotypes for salt tolerance. International Journal of Plant, Animal and Environmental Sciences 4: 23-30.

[2] Amirjani, M. (2010): Effect of salinity stress on growth, mineral composition, proline content, antioxidant enzymes of soybean. - American Journal of Plant Physiology 5: 350360 .

[3] Ashraf, M., Foolad, M. (2007): Roles of glycine betaine and proline in improving plant abiotic stress resistance. - Environmental and Experimental Botany 59: 206-216.

[4] Ashraf, M., Shahzad, S. M., Imtiaz, M., Rizwan, M. S., Arif, M. S., Kausar, R. (2018): Nitrogen nutrition and adaptation of glycophytes to saline environment: a review. Archives of Agronomy and Soil Science 64: 1181-1206.

[5] Ashraf, M. A., Ashraf, M., Shahbaz, M. (2012): Growth stage-based modulation in antioxidant defense system and proline accumulation in two hexaploid wheat (Triticum aestivum L.) cultivars differing in salinity tolerance. - Flora-Morphology, Distribution, Functional Ecology of Plants 207: 388-397.

[6] Asrar, H., Hussain, T., Hadi, S. M. S., Gul, B., Nielsen, B. L., Khan, M. A. (2017): Salinity induced changes in light harvesting and carbon assimilating complexes of Desmostachya bipinnata (L.) Staph. - Environmental and Experimental Botany 135: 8695.

[7] Azeem, A., Wu, Y., Javed, Q., Xing, D., Ullah, I., Kumi, F. (2017a): Response of okra based on electrophysiological modeling under salt stress and re-watering. - Bioscience Journal 33(5):1219-1229.

[8] Azeem, A., Wu, Y., Xing, D., Javed, Q., Ullah, I. (2017b): Photosynthetic response of two okra cultivars under salt stress and re-watering. - Journal of Plant Interactions 12: 67-77.

[9] Chen, L., Yu, Y., He, X. (2008): Historical invasion and expansion process of Alternaria philoxeroides and its potential spread in China. - Biodiversity Science 16: 578-585.

[10] Chen, Z., Zou, Y., Chen, Y., Zhang, Z., Xu, X. (2010): Effects of fragmentation intensity of perennial roots and their burial depth on sprouting and early growth of Alternanthera philoxeroides (Mart.) Griseb. - Agricultural Science, Technology-Hunan 11: 103-111.

[11] Croser, C., Renault, S., Franklin, J., Zwiazek, J. (2001): The effect of salinity on the emergence and seedling growth of Picea mariana, Picea glauca, and Pinus banksiana. Environmental Pollution 115: 9-16.

[12] Dong, B.-C., Yu, G.-L., Guo, W., Zhang, M.-X., Dong, M., Yu, F.-H. (2010): How internode length, position and presence of leaves affect survival and growth of Alternanthera philoxeroides after fragmentation? - Evolutionary Ecology 24: 1447-1461.

[13] Drenovsky, R. E., Khasanova, A., James, J. J. (2012): Trait convergence and plasticity among native and invasive species in resource-poor environments. - American Journal of Botany 99: 629-639.

[14] Flexas, J., Loreto, F., Medrano, H. (2012): Terrestrial Photosynthesis in a Changing Environment: A Molecular, Physiological, and Ecological Approach. - Cambridge University Press, New York.

[15] Gioria, M., Osborne, B. A. (2014): Resource competition in plant invasions: emerging patterns and research needs. - Frontiers in Plant Science 5: 501. 
[16] Gunasekera, L. (2008): Sessile joyweed (Alternanthera sessilis): a popular leafy vegetable in South East Asia but federal noxious weed in USA. - Proceedings of the 16th Australian Weed Conference, Cairns, Queensland, 18-22 May 2008.

[17] Habib, N., Ashraf, M., Ali, Q., Perveen, R. (2012): Response of salt stressed okra (Abelmoschus esculentus Moench) plants to foliar-applied glycine betaine and glycine betaine containing sugarbeet extract. - South African Journal of Botany 83: 151-158.

[18] Hemakanthi De Alwis, G., Wijesekera, R., Jayasekera, T. (2006): Use patterns and residue levels of pesticides on mukunuwenna, a leafy vegetable grown in Sri Lanka. Bulletin of Environmental Contamination and Toxicology 76: 119-125.

[19] Javed, Q., Wu, Y., Azeem, A., Ullah, I. (2017a): Evaluation of irrigation effects using diluted salted water based on electrophysiological properties of plants. - Journal of Plant Interactions 12: 219-227.

[20] Javed, Q., Wu, Y., Xing, D., Azeem, A., Ullah, I., Zaman, M. (2017b): Re-watering: An effective measure to recover growth and photosynthetic characteristics in salt-stressed Brassica napus L. - Chilean Journal of Agricultural Research 77: 78-86.

[21] Javed, Q., Wu, Y., Xing, D., Ullah, I., Azeem, A., Rasool, G. (2018): Salt-induced effects on growth and photosynthetic traits of Orychophragmus violaceus and its restoration through re-watering. - Brazilian Journal of Botany 41: 29-41.

[22] Keser, L. H., Visser, E. J., Dawson, W., Song, Y.-B., Yu, F.-H., Fischer, M., Dong, M., Van Kleunen, M. (2015): Herbaceous plant species invading natural areas tend to have stronger adaptive root foraging than other naturalized species. - Frontiers in Plant Science 6: 273 .

[23] Kolb, A., Alpert, P. (2003): Effects of nitrogen and salinity on growth and competition between a native grass and an invasive congener. - Biological Invasions 5: 229-238.

[24] Kosma, D. K., Jenks, M. A. (2007): Eco-physiological and Molecular-Genetic Determinants of Plant Cuticle Function in Drought and Salt Stress Tolerance. - In: Jenks, M. A., Hasegawa, P. M., Jain, S. M. (eds.) Advances in Molecular Breeding toward Drought and Salt Tolerant Crops. Springer, Dordrecht

[25] Liu, Y., Liu, M., Xu, X., Tian, Y., Zhang, Z., Van Kleunen, M. (2018): The effects of changes in water and nitrogen availability on alien plant invasion into a stand of a native grassland species. - Oecologia 188: 441-450.

[26] Lorenzo, P., González, L., Reigosa, M. J. (2010): The genus Acacia as invader: the characteristic case of Acacia dealbata Link in Europe. - Annals of Forest Science 67: 101.

[27] Meloni, D. A., Gulotta, M. R., Martínez, C. A., Oliva, M. A. (2004): The effects of salt stress on growth, nitrate reduction and proline and glycinebetaine accumulation in Prosopis alba. - Brazilian Journal of Plant Physiology 16: 39-46.

[28] Memon, S. A., Hou, X., Wang, L. J. (2010): Morphological analysis of salt stress response of pak choi. - Electronic Journal of Environmental, Agricultural, Food Chemistry 9(1): 248-254.

[29] Morais, M. C., Panuccio, M. R., Muscolo, A., Freitas, H. (2012): Salt tolerance traits increase the invasive success of Acacia longifolia in Portuguese coastal dunes. - Plant Physiology and Biochemistry 55: 60-65.

[30] Munns, R., Tester, M. (2008): Mechanisms of salinity tolerance. - Annual Review of Plant Biology 59: 651-681.

[31] Nawaz, K., Hussain, K., Majeed, A., Khan, F., Afghan, S., Ali, K. (2010): Fatality of salt stress to plants: Morphological, physiological and biochemical aspects. - African Journal of Biotechnology 9(34): 5475-5480.

[32] Niraimathi, K., Sudha, V., Lavanya, R., Brindha, P. (2013): Biosynthesis of silver nanoparticles using Alternanthera sessilis (Linn.) extract and their antimicrobial, antioxidant activities. - Colloids and Surfaces B: Biointerfaces 102: 288-291. 
[33] Noe, G. B., Zedler, J. B. (2001): Spatio-temporal variation of salt marsh seedling establishment in relation to the abiotic and biotic environment. - Journal of Vegetation Science 12: 61-74.

[34] Ozaslan, C., Farooq, S., Onen, H., Bukun, B., Ozcan, S., Gunal, H. (2016): Invasion Potential of Two Tropical Physalis Species in Arid and Semi-Arid Climates: Effect of Water-Salinity Stress and Soil Types on Growth and Fecundity. - PloS one 11: e0164369.

[35] Qian, H., Ricklefs, R. E. (2006): The role of exotic species in homogenizing the North American flora. - Ecology Letters 9: 1293-1298.

[36] Quinet, M., Descamps, C., Coster, Q., Lutts, S., Jacquemart, A.-L. (2015): Tolerance to water stress and shade in the invasive Impatiens parviflora. - International Journal of Plant Sciences 176: 848-858.

[37] Ricciardi, A., Blackburn, T. M., Carlton, J. T., Dick, J. T., Hulme, P. E., Iacarella, J. C., Jeschke, J. M., Liebhold, A. M., Lockwood, J. L., Macisaac, H. J. (2017): Invasion science: a horizon scan of emerging challenges and opportunities. - Trends in Ecology, Evolution 32: 464-474.

[38] Richards, C. L., Bossdorf, O., Muth, N. Z., Gurevitch, J., Pigliucci, M. (2006): Jack of all trades, master of some? On the role of phenotypic plasticity in plant invasions. - Ecology Letters 9: 981-993.

[39] Schooler, S. S. (2012): Alternanthera Philoxeroides (Martius) Grisebach (Alligator Weed). - In: Francis, R. A. (ed.) A Handbook of Global Freshwater Invasive Species. Routledge, London.

[40] Schweiger, O., Biesmeijer, J. C., Bommarco, R., Hickler, T., Hulme, P. E., Klotz, S., Kühn, I., Moora, M., Nielsen, A., Ohlemüller, R. (2010): Multiple stressors on biotic interactions: how climate change and alien species interact to affect pollination. Biological Reviews 85: 777-795.

[41] Sekmen, A. H., Tuerkan, I., Takio, S. (2007): Differential responses of antioxidative enzymes and lipid peroxidation to salt stress in salt-tolerant Plantago maritima and saltsensitive Plantago media. - Physiologia Plantarum 131: 399-411.

[42] Sun, Y., Ding, J., Frye, M. (2010): Effects of resource availability on tolerance of herbivory in the invasive Alternanthera philoxeroides and the native Alternanthera sessilis. - Weed Research 50: 527-536.

[43] Van Kleunen, M., Weber, E., Fischer, M. (2010): A meta-analysis of trait differences between invasive and non-invasive plant species. - Ecology Letters 13: 235-245.

[44] Vilà, M., Espinar, J. L., Hejda, M., Hulme, P. E., Jarošík, V., Maron, J. L., Pergl, J., Schaffner, U., Sun, Y., Pyšek, P. (2011): Ecological impacts of invasive alien plants: a meta-analysis of their effects on species, communities and ecosystems. - Ecology Letters 14: 702-708.

[45] Vitousek, P. M., Aber, J. D., Howarth, R. W., Likens, G. E., Matson, P. A., Schindler, D. W., Schlesinger, W. H., Tilman, D. G. (1997): Human alteration of the global nitrogen cycle: sources and consequences. - Ecological Applications 7: 737-750.

[46] Weed, A. S., Schwarzländer, M. (2014): Density dependence, precipitation and biological control agent herbivory influence landscape-scale dynamics of the invasive Eurasian plant Linaria dalmatica. - Journal of Applied Ecology 51: 825-834.

[47] Xing, D., Wu, Y., Yu, R., Wu, Y., Javed, Q. (2018): Determination of appropriate irrigation time based on rewatering water-use efficiency. - Acta Horticulturae. DOI: 10.17660/ActaHortic.2018.1205.43

[48] Yang, C., Yang, X., Zhang, X., Zhou, C., Zhang, F., Wang, X. E., Wang, Q. (2019): Anatomical structures of alligator weed (Alternanthera philoxeroides) suggest it is well adapted to the aquatic-terrestrial transition zone. - Flora 253: 27-34.

[49] You, W.-H., Fang, L.-X., Xi, D.-G., Du, D.-L., Xie, D. (2018): Difference in capacity of clonal integration between terrestrial and aquatic Alternanthera philoxeroides in response to defoliation: implications for biological control. - Hydrobiologia 817: 319-328. 
[50] Yousfi, N., Sihem, N., Ramzi, A., Abdelly, C. (2016): Growth, photosynthesis and water relations as affected by different drought regimes and subsequent recovery in Medicago laciniata (L.) populations. - Journal of Plant Biology 59: 33-43.

[51] Zaki, S. (2016): Effect of compost and nitrogen fertilization on yield and nutrients uptake of rice crop under saline soil. - Modern Chemistry and Application 4: 183.

[52] Zenni, R. D., Ziller, S. R., Pauchard, A., Rodriguez-Cabal, M., Nuñez, M. A. (2017): Invasion science in the developing world: a response to Ricciardi et al. - Trends in Ecology, Evolution 32: 807-808.

[53] Zheng, Y.-L., Feng, Y.-L., Liu, W.-X., Liao, Z.-Y. (2009): Growth, biomass allocation, morphology, and photosynthesis of invasive Eupatorium adenophorum and its native congeners grown at four irradiances. - Plant Ecology 203: 263-271. 